\title{
Screening for phenotype selective activity in multidrug resistant cells identifies a novel tubulin active agent insensitive to common forms of cancer drug resistance
}

\author{
Mårten Fryknäs ${ }^{1 \dagger}$, Joachim Gullbo ${ }^{1 \dagger}$, Xin Wang ${ }^{3 \dagger}$, Linda Rickardson ${ }^{1}$, Malin Jarvius ${ }^{1}$, Malin Wickström', Saadia Hassan ,
} Claes Andersson ${ }^{1}$, Mats Gustafsson', Gunnar Westman ${ }^{4}$, Peter Nygren², Stig Linder ${ }^{3}$ and Rolf Larsson ${ }^{1 *}$

\begin{abstract}
Background: Drug resistance is a common cause of treatment failure in cancer patients and encompasses a multitude of different mechanisms. The aim of the present study was to identify drugs effective on multidrug resistant cells.

Methods: The RPMI 8226 myeloma cell line and its multidrug resistant subline 8226/Dox40 was screened for cytotoxicity in response to 3,000 chemically diverse compounds using a fluorometric cytotoxicity assay (FMCA). Follow-up profiling was subsequently performed using various cellular and biochemical assays.

Results: One compound, designated VLX40, demonstrated a higher activity against 8226/Dox40 cells compared to its parental counterpart. VLX40 induced delayed cell death with apoptotic features. Mechanistic exploration was performed using gene expression analysis of drug exposed tumor cells to generate a drug-specific signature. Strong connections to tubulin inhibitors and microtubule cytoskeleton were retrieved. The mechanistic hypothesis of VLX40 acting as a tubulin inhibitor was confirmed by direct measurements of interaction with tubulin polymerization using a biochemical assay and supported by demonstration of G2/M cell cycle arrest. When tested against a broad panel of primary cultures of patient tumor cells (PCPTC) representing different forms of leukemia and solid tumors, VLX40 displayed high activity against both myeloid and lymphoid leukemias in contrast to the reference compound vincristine to which myeloid blast cells are often insensitive. Significant in vivo activity was confirmed in myeloid U-937 cells implanted subcutaneously in mice using the hollow fiber model.
\end{abstract}

Conclusions: The results indicate that VLX40 may be a useful prototype for development of novel tubulin active agents that are insensitive to common mechanisms of cancer drug resistance.

Keywords: Screening, Myeloma cell lines, Primary cultures, Drug resistance, Tubulin inhibition

\section{Background}

Current treatment strategies for treatment of cancer are limited by the occurrence of drug resistance [1-3]. The cellular mechanisms have been extensively studied in cell line models and include alterations of drug transport, metabolism, DNA synthesis and repair, cell survival and apoptosis. Both genetic and epigenetic changes may

\footnotetext{
* Correspondence: rolf.larsson@medsci.uu.se

${ }^{\dagger}$ Equal contributors

'Department of Medical Sciences, Division of Clinical Pharmacology, Uppsala University, S-751 85 Uppsala, Sweden

Full list of author information is available at the end of the article
}

be involved in determining the balance between drug sensitivity and resistance $[4,5]$. Consequently, novel therapies avoiding these mechanisms are urgently needed.

During the past decades most screening approaches for identification of new cancer drug candidates have utilized cell free assays for detection of specific interactions with known or emerging molecular targets [6]. However, the relatively poor outcome with respect to identification of clinically novel and significantly improved cancer drugs has led to a renewed and growing interest for cancer drug screening based on compound induced changes in cellular phenotypes [7-9]. Cultures of human tumor cell lines

\section{() Bïomed Central}

(c) 2013 Fryknäs et al.; licensee BioMed Central Ltd. This is an Open Access article distributed under the terms of the Creative Commons Attribution License (http://creativecommons.org/licenses/by/2.0), which permits unrestricted use, distribution, and reproduction in any medium, provided the original work is properly cited. 
have been the general model in these efforts and are important tools for predicting mechanisms of drug action as demonstrated in numerous reports [7,9]. Furthermore, recent results utilizing very large panels of cell lines indicate that they also to a large extent retain genomic features of the primary tumor and can recapitulate clinical findings with regard to their response to targeted inhibitors [9].

We have previously utilized the myeloma cell line RPMI 8226 and its multidrug resistant (MDR) 8226/Dox40 subline for phenotype selective activity in response to an annotated compound library [10]. The 8226/Dox40 subline over expresses P-glycoprotein [11], but also other mechanisms are likely contributing to the multidrug resistant phenotype [12]. We have also previously demonstrated that over expression of STAT1-regulated genes contribute to doxorubicin resistance observed in 8226/Dox40 cells $[13,14]$.

In the present study the same myeloma cell lines were tested in response to 3,000 chemically diverse compounds to explore the possibility of finding compounds selectively active against the MDR phenotype. After hit validation and counter screening one hit compound, VLX40, was selected for mechanistic investigation and further preclinical evaluation.

\section{Methods}

\section{Cell culture}

For primary screening RPMI 8226 and its multidrug resistant cell line 8226/Dox40 were used. In a secondary screen, a cell line panel representing different drug resistance phenotypes was used (described in Table 1). The cell lines of this panel were cultured and harvested as previously described [14].

An additional 98 primary cultures of primary human tumor cells (PCPTCs) from different tumor types, and four preparations of normal peripheral blood mononuclear cells (PBMC), detailed in Table 2, were used to determine the
Table 2 Median $\mathrm{IC}_{50}$ for different diagnoses in response to VLX40

\begin{tabular}{lll}
\hline Diagnosis & Median $\mathbf{I C}_{\mathbf{5 0}}(\boldsymbol{\mu M})$ & Number of samples \\
\hline Breast cancer & $>34$ & 8 \\
Colon cancer & $>34$ & 5 \\
Lung cancer & $>34$ & 6 \\
Renal cancer & $>34$ & 8 \\
Ovarian cancer & $>34$ & 19 \\
AML & 1.56 & 8 \\
ALL & 3.21 & 19 \\
CML & 0.98 & 2 \\
CLL & 2.18 & 11 \\
NHL & 0.51 & 13 \\
PBMC & 16.3 & 4 \\
\hline
\end{tabular}

activity spectrum of VLX40 and, for comparison, six standard cytotoxic drugs chosen to represent different mechanistic classes. The tumor samples were obtained by bone marrow/peripheral blood sampling, routine surgery or diagnostic biopsy. Leukemic cells and PBMCs were isolated by $1.077 \mathrm{~g} / \mathrm{ml}$ Ficoll-Paque centrifugation [20]. Tumor tissue from solid tumor samples was minced into small pieces and tumor cells were isolated by collagenase dispersion followed by Percoll density gradient centrifugation [21]. The patient sampling was approved by the Regional Ethics Board, Uppsala, Sweden. Cell viability was determined by trypan blue exclusion test and the proportion of tumor cells in the preparation was judged by inspection of May-Grunwald-Giemsa stained cytospin slides. All samples used in this study contained more than $70 \%$ tumor cells.

The human cell lines used for mechanistic studies were MCF7 (breast cancer), HCT 116 (colon cancer) and hTERT-RPE-1 (normal epithelial cell line). MCF7, HCT 116 and HL-60 were obtained from American Type Culture Collection (ATCC, Rockville, MD) whereas

Table 1 Cell line panel representing different types of drug resistance

\begin{tabular}{|c|c|c|c|c|c|}
\hline Cell line & Diagnosis & Selective agent & Mechanism of resistance & P-gp expression* & Reference \\
\hline RPMI 8226 & Myeloma & & & 82 & \\
\hline 8226/Dox40 & Myeloma & Doxorubicin & P-gp170 & 27002 & {$[11,15]$} \\
\hline 8226/LR5 & Myeloma & Melphalan & GSH associated & Not expressed ${ }^{* *}$ & [16] \\
\hline CCRF-CEM & T-cell leukemia & & & Not expressed** & \\
\hline CEMNM-1 & T-cell leukemia & Teniposode & Topo II associated & Not expressed** & {$[17]$} \\
\hline $\mathrm{NCl}-\mathrm{H} 69$ & Small cell lung cancer & & & Not expressed ${ }^{* *}$ & \\
\hline H69AR & Small cell lung cancer & Doxorubicin & MRP associated & Not expressed** & [18] \\
\hline U-937 & Histiocytic lymphoma & & & Not expressed ${ }^{* *}$ & \\
\hline U-937-ver & Histiocytic lymphoma & Vincristine & Tubulin associated & 875 & [19] \\
\hline
\end{tabular}


hTERT-RPE-1 was from Clontech (Palo Alto, CA). In the in vivo hollow fiber studies the myelocytic cell line U-937 was used. The normal epithelial hTERT-RPE-1 cells were cultured in Dulbecco's Modified Eagles Medium nutrient mixture F-12 Ham, supplemented with 10\% heat-inactivated fetal calf serum, $2 \mathrm{mM}$ glutamine, $100 \mu \mathrm{g} / \mathrm{ml}$ streptomycin and $100 \mathrm{U} / \mathrm{ml}$ penicillin (all from Sigma Aldrich Co, St Louis, $\mathrm{MO}$ ) at $37^{\circ} \mathrm{C}$ in humidified air containing $5 \% \mathrm{CO}_{2}$. MCF-7 was grown in in Eagle's Minimal Essential Medium, supplemented as above. HCT116 were grown in complete McCoy's medium. RPMI 8226, 8226/Dox40, HL-60 and U-937 were grown in complete RPMI medium.

\section{Preparation of compounds for screening}

The Maybridge Hitskit 3000 library (Maybridge Inc) consists of 3000 chemically diverse compounds. The library was delivered in 36 racks each containing 80 compounds dissolved in DMSO to $10 \mathrm{mg} / \mathrm{ml}$. For the screening, aliquots of the DMSO solutions were transferred to 96-well plates and were further diluted with PBS to obtain stock solutions of $100 \mu \mathrm{g} / \mathrm{ml}$ from which four different 384-well plates for screening were prepared with final test concentrations of $1 \mu \mathrm{g} / \mathrm{ml}$. In all steps, the Biomek 2000 pipetting station connected to a plate stacker carousel (Beckman Coulter Inc, Fullerton, CA) in a safety cabinet (Bigneat Inc, Hampshire, UK) was used. For dose-response studies, plates containing VLX40 (Vivolux AB, Uppsala, Sweden) and other compounds were prepared by 10 -fold serial dilutions in the concentrations 0.004 to $40 \mu \mathrm{M}$ using the same robotic system. The plates were stored at $-70^{\circ} \mathrm{C}$ until further use. The screening identified one compound with higher activity against 8226/Dox40 cells compared to its parental counterpart RPMI 8226. This compound, chemically a quinoline alkaloid (2-phenyl-4-hydroxyquinoline-6carboxylic acid ethyl ester), was designated VLX40, and subjected for detailed studies.

\section{Measurement of cancer drug activity}

The Fluorometric Microculture Cytotoxicity Assay, FMCA, described in detail previously [22], was used for measurement of the cytotoxic effect of library compounds and the established standard drugs. The FMCA is based on measurement of fluorescence generated from hydrolysis of fluorescein diacetate (FDA) to fluorescein by cells with intact plasma membranes. Cells were seeded in the drugprepared 384-well plates using the pipetting robot Precision 2000 (Bio-Tek Instruments Inc., Winooski, VT). The number of cells per well was 2,500 - 5,000 for solid tumor samples and 10,000 - 20,000 for leukemic samples. In each plate, two columns without drugs served as controls and one column with medium only served as blank.

The plates were incubated for $72 \mathrm{~h}$ and then transferred to an integrated HTS SAGIAN Core System consisting of an ORCA robot (Beckman Coulter) with $\mathrm{CO}_{2}$ incubator (Cytomat 2C, Kendro, Sollentuna, Sweden), dispenser module (Multidrop 384, Titertek, Huntsville, AL), washer module (ELx 405, Bio-Tek Instruments Inc), de-lidding station, plate hotels, barcode reader (Beckman Coulter), liquid handler (Biomek 2000, Beckman Coulter) and a multipurpose reader (FLUOstar Optima, BMG Labtech $\mathrm{GmbH}$, Offenburg, Germany) for automated FMCA. Quality criteria for a successful assay included a mean coefficient of variation of less than $30 \%$ in the control wells and a fluorescence signal in control wells of more than 5 times the blank (10 times for cell lines). Survival index (SI) is defined as the fluorescence of test wells in percentage of controls with blank values subtracted.

\section{Multiparametric high content evaluation of apoptosis and cell cycle arrest}

The fluorescence microscope ArrayScan High Content Screening (HCS) system (Cellomics Inc., Pittsburgh, PA, USA) was used to study apoptosis and cell cycle arrest. For these assays, cells were seeded into 96-well plates (PerkinElmer Inc., Wellesley, MA, USA), left to attach over night, before test compounds were added.

Cell death characteristics were studied using a multiparametric HCS assay described in detail previously [23]. Apoptosis was evaluated after 6, 24 and $48 \mathrm{~h}$ exposure to VLX40 in MCF-7 cells. The FLICA probe FAMDEVD-FMK (carboxyfluorescein-labeled fluoromethyl ketone peptide inhibitor of caspase-3; at a final concentration of $20 \mu \mathrm{M}$ ) was added $1 \mathrm{~h}$ before the end of the drug exposure to stain activated caspase-3/7. Plates were then washed and nuclei stained with $10 \mu \mathrm{M}$ Hoechst 33342 in a fixation solution with $3.7 \%$ formaldehyde.

To study cell cycle arrest, HCT116 cells were incubated for 24 h with VLX40. Cells were stained using Cell Cycle Kit I reagents for DNA content and phospho-histone H3 staining (Thermo Fisher Scientific) according to the manufacturer's instructions. Primary antibodies specific for phospho-histone H3 (rabbit), secondary antibodies DyLight 549 Conjugated Goat anti-Rabbit IgG and DAPI dye were used.

Processed plates were loaded in the ArrayScan and analyzed. Images were acquired for each fluorescence channel, using suitable filters with 10X or 20X objective and in each well at least 1000 cells were analyzed. Quantification of apoptosis was performed by measuring caspase- 3 activation and nuclear fragmentation, wheras quantification of cell cycle arrest was obtained by nuclear DNA content (mean average intensity of DAPI) and phospho-histone H3 (total intensity).

\section{Flow cytometry analysis of cell cycle and apoptosis}

Cells were seeded in 24- well plates $24 \mathrm{~h}$ prior to treatment with different concentrations of VLX40 for 6, 16, 24 and 
48 hours. Upon drug exposure, cells were washed with PBS and stained with Annexin V-FITC according to the instructions of the vendor (Annexin V-FITC apoptosis detection kit 556547, BD Pharmingen). Cell cycle analysis was performed by labeling digitonin-permeabilized cells with $5 \mathrm{ug} / \mathrm{ml}$ propidium iodide. Flow cytometry analysis was performed using a BD LSR II flow cytometer.

\section{Phase contrast microscopy}

Time-lapse phase contrast microscopy was performed using an automated IncuCyte phase contrast microscope (Essen Instruments, Ann Arbor, MI). MCF-7 cells (10,000/ well) were plated on 24-well ImageLock plates (Essen Instruments) and immediately placed into the IncuCyte imaging system. The chamber is designed to fit into a standard, humidified incubator in an atmosphere of 5\% $\mathrm{CO}_{2}$, and a moving objective allows the cell culture to be stationary while images are captured at different positions from well to well. Images were collected at $1 \mathrm{~h}$ intervals starting $30 \mathrm{~min}$ after placing the plate in the IncuCyte chamber and cells were left to attach for $24 \mathrm{~h}$ when drug treatment was performed. Cell density (i.e. confluence) was calculated using the IncuCyte software.

\section{Microarray analysis}

RNA from cell cultures was isolated using RNeasy Mini Kit from Qiagen and immediately stored at $-70^{\circ} \mathrm{C}$ until further use. RNA purity and quality was measured using an ND 1000 spectrophotometer (NanoDrop Tecnhologies, Wilmington, DE) and Bioanalyzer 2100 (Agilent Technologies Inc, Palo Alto, CA, USA), respectively. Starting from $2 \mu \mathrm{g}$ of total RNA, gene expression analysis was performed using Genome U133 Plus 2.0 Arrays according to the GeneChip Expression Analysis Technical Manual (Rev. 5, Affymetrix Inc., Santa Clara, CA). Raw data was normalized using MAS5 (Affymetrix Inc.). Connectivity Map (cmap) build 02 (www.broad.mit.edu/cmap) contains genome-wide expression data for 1,309 compounds $(6,100$ entries, including replicates, different doses and cell lines). The original protocol using MCF-7 breast cancer cells as described by Lamb et al. was used [24]. Briefly, cells were seeded in a 6 -well plate at a density of $0.4 \times 10^{6}$ cells per well. Cells were left to attach for $24 \mathrm{~h}$, followed by exposure to either VLX40 at a final concentration of $10 \mu \mathrm{M}$, or to vehicle control (DMSO). After $6 \mathrm{~h}$ the cells were washed with PBS and total RNA was prepared. Gene expression ratios for drug treated vs. control cells were calculated to generate a list of regulated genes. This list was further filtrated using the flags from the MAS5 normalization. Only probes with signals over 300 arbitrary units and present call in both VLX40 treated and vehicle control were used in the Gene Set Enrichment Analysis (GSEA). In the cmap analysis, only probes present on HG
U133A were used, for cmap compatibility. The 20 most up and the 10 most down regulated genes (i.e. probes) were uploaded into the cmap and compared to the 6,100 instances in the cmap database, to retrieve a list of compounds with similar response profile as VLX40. The GSEA software and method for microarray result exploration has been described elsewhere [25]. Briefly, the pre-ranked list (VLX40 exposed MCF-7 cells vs. untreated control, described above) was compared to a priori defined and curated gene sets $(\mathrm{C} 2)$. The p-value refers to the nominal p-value after 1000 permutations.

\section{Measurements of tubulin polymerization}

Tubulin polymerization from purified tubulin monomers was measured as increased fluorescence because of the incorporation of a fluorescent reporter into growing microtubules. All reagents necessary for performing the assay were provided in the kit BK011 from Cytoskeleton (Denver, Colorado, USA). The fluorescence was measured at 1-min intervals for $60 \mathrm{~min}$ using a FLUOstar Optima (BMG Labtech GmbH, Offenburg, Germany).

\section{Immunological assays}

Spheroids produced by the hanging drop method in 96 well plates were fixed in paraformaldehyde, dehydrated, embedded in paraffin and sectioned and stained for Ki67 and active caspase-3, as previously described [26].

\section{In vivo studies}

Myeloid U-937 cells were cultured inside semi-permeable polyvinylidene fluoride fibers and assessed in the hollow fiber assay [27,28]. The fibers were implanted subcutaneously into the back of immunocompetent animals (male NMRI mice, Scanbur, Sollentuna Sweden). The following day each mouse was treated with a single subcutaneous injection of VLX40 at a dose of either $0.5 \mu \mathrm{mol} / \mathrm{animal}$ $(\mathrm{n}=8), 2 \mu \mathrm{mol} /$ animal $(\mathrm{n}=8)$, or vehicle $(\mathrm{n}=8)$. Fibers were retrieved after 6 days and cell density evaluated using the MTT (3-[4,5-dimethylthiazol-2-yl]-2,5-diphenyltetrazolium bromide)-assay [29]. The method is based on the conversion of MTT to blue formazan crystals by living cells. The formazan was extracted by DMSO as previously described [28], and optical density (OD) read at $570 \mathrm{~nm}$. Cell density for each fiber on retrieval day was expressed as net growth, defined as (OD retrieval day - OD implantation day)/OD implantation day $\times 100$, i.e. the percent change in cell density in the fibers during the 6 days of in vivo experiment. The animals were observed regarding behavior and weight gain throughout the experiment. $200 \mu \mathrm{l}$ blood samples were obtained through the orbital plexus after anesthetization with isofluran just before euthanasia, and analyzed for hematological parameters. Animals were caged four in each cage and fed a commercial diet (Lactamin AB, Sweden), with water given ad libitum. The 
study was approved by the Animal Ethics Committee in Uppsala, Sweden.

\section{Data analysis and statistics}

Screening data was exported to Vortex (Dotmatics Inc, UK) software for analysis. A Survival Index of less than 50\% in myeloma 8226/Dox 40 and more than $50 \%$ in parental RPMI 8226 cells was set as the criteria for qualifying as a hit compound.

Concentration-response data of screening hits and standard agents were analyzed using the software GraphPadPrism4 (GraphPad Software Inc., San Diego, CA, USA). Data was processed using non-linear regression to a standard sigmoidal dose-response model to obtain $\mathrm{IC}_{50}$-values (the concentration resulting in a SI of 50\%).

Response rate in PCPTCs of a specific diagnosis was defined as the fraction of samples having an SI below the median, calculated from all PCPTSs included in the study, at the drug concentration showing the largest SD in survival (SI). For VLX40 this concentration was 3.4 $\mu \mathrm{M}$. The data for the reference compound vincristine was taken from Lindhagen et al [30], and recalculated as response rate at $1 \mu \mathrm{M}$. The PCPTC samples used are listed in Table 2. The relative effect of a drug on solid compared with hematological tumors was indicated by the $\mathrm{S} / \mathrm{H}$ ratio, defined as the ratio between the total response rates for the solid and the hematological samples. Tumor cell specific activity was estimated by calculation of the ratio of the median $\mathrm{IC}_{50}$-value for $\mathrm{PBMC}$ over that of chronic lymphocytic leukemia (CLL) samples. Comparisons between groups in the hollow fiber experiment were done with Student's $t$-test.

\section{Results}

\section{Drug screening using multidrug-resistant myeloma cells}

We here used 8226/Dox40 myeloma cells as a model for drug resistance. Multiple mechanisms, including overexpression of P-glycoprotein, have been shown to contribute to the drug resistant phenotype [11-14]. A library of 3,000 chemically diverse compounds was used for screening of 8226/Dox40 and parental RPMI 8226 cells at a concentration of $1 \mu \mathrm{g} / \mathrm{ml}$, and cytotoxic/antiproliferative activity was determined using FMCA (Figure 1A). One compound, RH02104 (Figure 1B) (subsequently denoted VLX40), demonstrated phenotype selective activity for the 8226/Dox 40 subline.

A cell line panel of different origins, characterized by different mechanisms of drug resistance (Table 1), was tested for its sensitivity to VLX40 at $1 \mu \mathrm{g} / \mathrm{ml}$. We found that VLX40 was not sensitive to multidrug resistance protein (MRP)- or topoisomerase II (Topo II)-mediated drug resistance (Figure 1C). Furthermore, the U-937/vcr cell line, associated with resistance to tubulin inhibitors, was almost as sensitive to VLX40 as parental U-937 cells (Figure 1C). Finally, immortalized human epithelial hTERT-RPE- 1 cells were less sensitive to VLX40 at $1 \mu \mathrm{g} / \mathrm{ml}$. Further hit confirmation in extended dose-response testing of VLX40 confirmed the relatively higher sensitivity of 8226/Dox40 compared to parental RPMI 8226 (Figure 1D), the difference in IC 50 being statistically significant $(\mathrm{P}<0.05$, Students $t$-test). In contrast, 8226/ Dox40 cells are highly resistant to vincristine (Figure 1E). Based on these findings VLX40 was selected for further preclinical evaluation.

\section{VLX40 induces apoptosis in cancer cells}

We examined the response of both solid and hematological tumor cells to VLX40 (see further below). The response of the breast cancer cell line MCF-7 was studied using time-lapse phase contrast microscopy and multi-parameter analysis for cell death using Array Scan (Figure 2). A concentration-dependent effect on cell proliferation was observed (Figure 2A). Phase contrast images of treated cells showed a rounded-up morphology surrounded by a bright halo (Figure 2B). No increase in membrane permeability was observed at $6 \mathrm{~h}$, whereas increases were observed at 24 and $48 \mathrm{~h}$ (Figure 2C). In parallel, we observed an increase in DNA fragmentation and caspase3-like activity (using a DEVD-based substrate) at 24 and $48 \mathrm{~h}$ (Figure 2D and E).

Induction of apoptosis was confirmed by analysis of annexin V/propidium iodide staining (Figure 2F) in myeloma and myeloid leukemia cell lines (Figure 2F). RPMI 8226 and 8226/Dox40, U-937 and HL-60 cells were exposed to VLX40 for $24 \mathrm{hrs}$, stained and analysed by flow cytometry. Apoptosis was found to be reduced by inhibitors of caspase- 3 and caspase- 9 , showing involvement of the intrinsic apoptosis pathway (Figure 2G).

\section{Identification of VLX40 as a tubulin active agent}

Mechanistic exploration was performed by measurement of gene expression of drug treated tumor cell cultures (Figure 3). The breast cancer cell line MCF-7 was exposed to $10 \mu \mathrm{M}$ VLX40 or vehicle (DMSO) for 6 hours followed by microarray-based gene expression analysis. A drug specific query signature was generated and uploaded to the Connectivity Map (cmap), to find other compounds with similar mechanism of action. The VLX40 signature showed strongest similarity to known tubulin inhibitors such as fenbendazole, vinblastine, nocodazole and podophyllotoxin. In fact, all of the top seven compounds are tubulin inhibitors (Figure 3A) [31-34]. Gene set Enrichment analysis (GSEA) of genes induced by VLX40 showed significant association to mitosis (Figure 3B)

VLX40 induced a strong increase in phospho-histone H3 (Figure 3C) indicative of inhibition of mitosis and further cell cycle analysis demonstrated clear G2/M arrest in RPMI 8226 and 8226/Dox40 as well as in myeloid U-937 and 


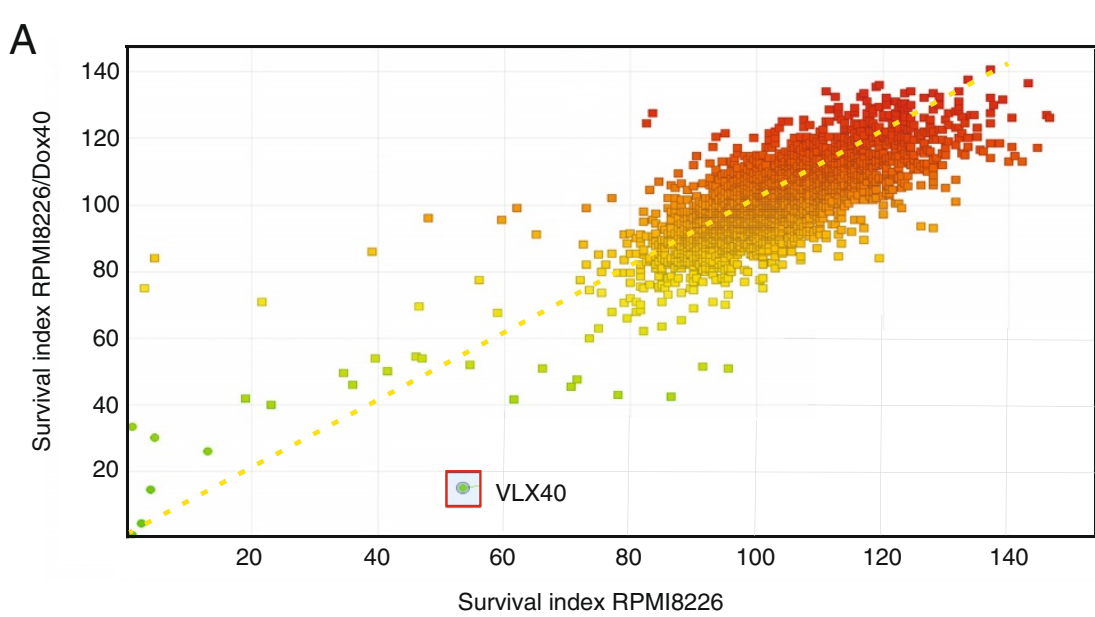

B<smiles>CCOC(=O)C1=CC2=CC(c3ccccc3)=CC(O)=CC2NC1</smiles>

Mol weight: Estimated Log. 3.75

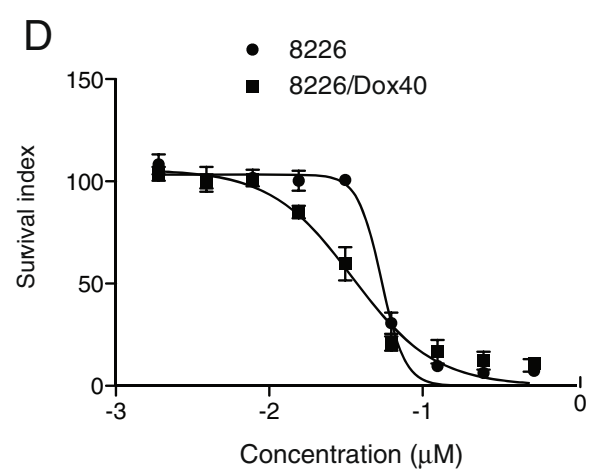

$\mathrm{C}$

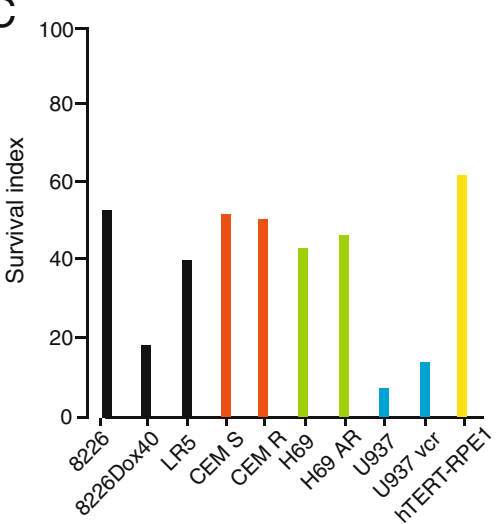

E

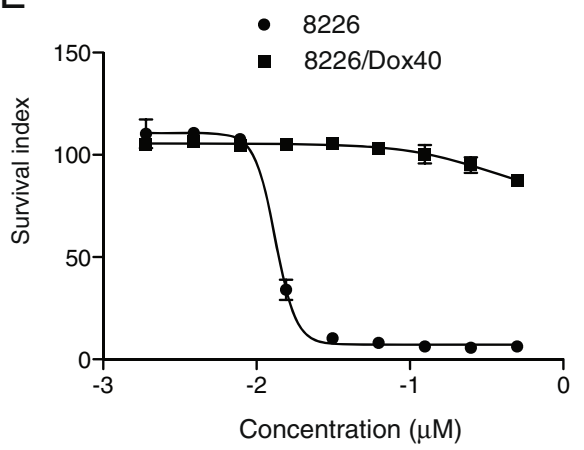

Figure 1 Drug screening in myeloma cell lines. (A) The overall screening results are displayed and expressed as survival index with results for 8226/Dox40 displayed on the Y axis and the parental RPMI 8226 cells on the X-axis. (B) Molecular structure and chemical properties of VLX40 (C) Activity of VLX40 against a cell line panel representing different forms of drug resistance. Cell survival was determined over $72 \mathrm{~h}$ using the FMCA assay in duplicate experiments. (D) Validation of VLX40 activity on 8226/Dox40 cells. Concentration-dependent effects of VLX40 on cell survival in RPMI 8226 (red line) and 8226/Dox40 (blue line) cell lines (triplicate samples). (E) Concentration-dependent effects of vincristine on cell survival in RPMI 8226 (red line) and 8226/Dox40 (blue line) cell lines. Survival in (D, E) was determined over $72 \mathrm{~h}$ using the FMCA assay. The results are expressed as percentage of the untreated control and presented as mean values + - - standard error of the mean (SEM) from three independent experiments.

HL-60 cells using flow cytometry (Figure 3D). The mechanistic hypothesis of VLX40 causing tubulin inhibition was subsequently confirmed by measuring tubulin polymerization in vitro. In this cell free assay both
VLX40 and the reference compound vincristine $(3 \mu \mathrm{M})$ clearly inhibited tubulin polymerization whereas paclitaxel $(3 \mu \mathrm{M})$, as expected, increased polymerization activity (Figure 3E). 


\section{A}

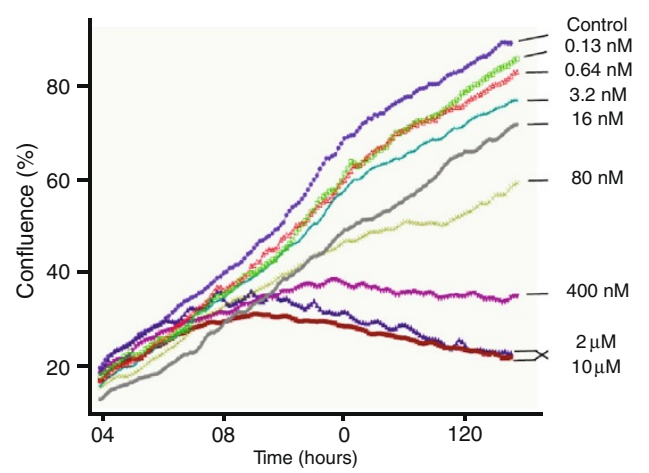

B

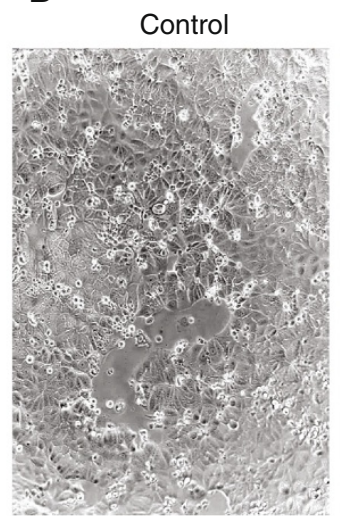

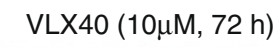

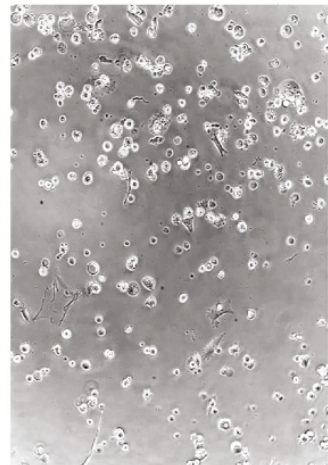

E

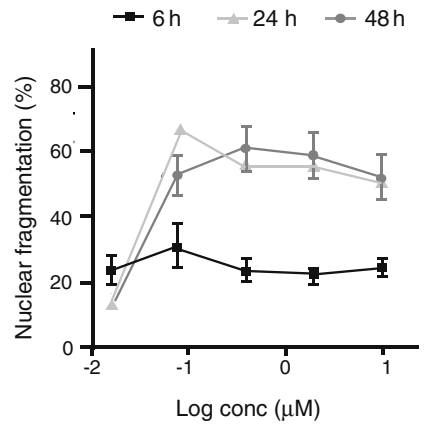

RPMI8226/Dox

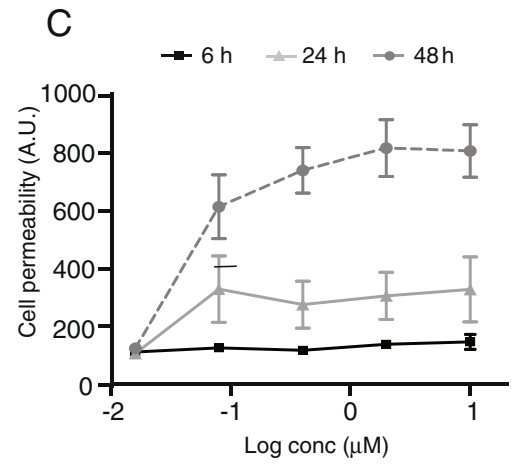

$\mathrm{F}$
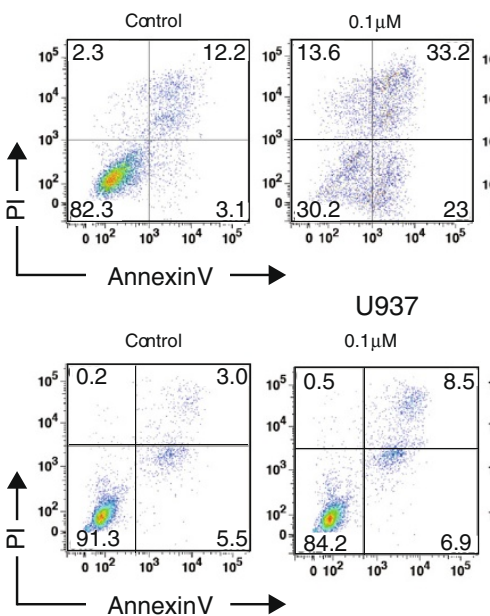

G

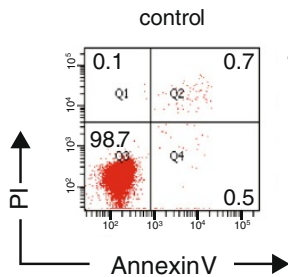

D

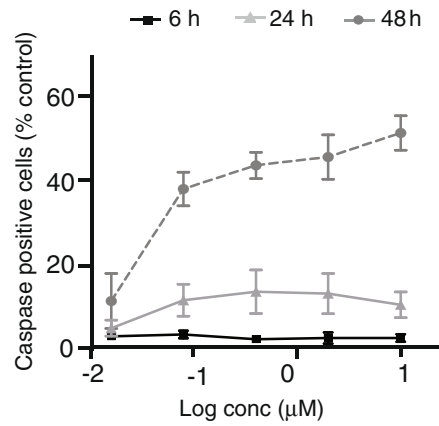

$0.1 \mu \mathrm{M}$

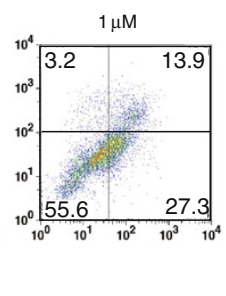

$\mathrm{HL}-60$

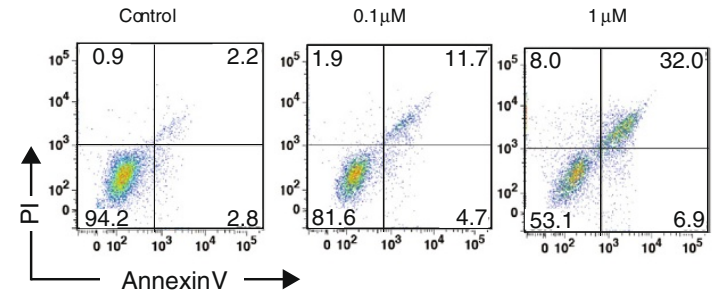

U937
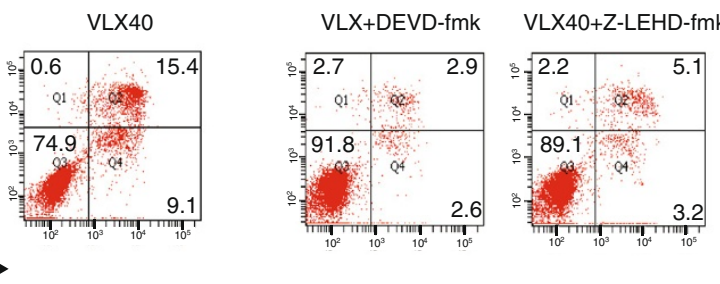

Figure $\mathbf{2}$ (See legend on next page.) 
(See figure on previous page.)

Figure 2 VLX40 induces apoptosis in the MCF-7 breast cancer cell line. In panel (A) cell growth kinetics were determined every hour during culture of MCF-7 tumor cells in 24-well plates. Cell confluence was determined by phase contrast time-lapse microscopy using an automated IncuCyte system. Representative phase contrast photomicrographs of control and VLX40 (10 $\mu \mathrm{M})$ exposed cultures after $72 \mathrm{~h}$ are shown in panel (B). Using Array Scan II the effects of VLX40 on membrane permeability (C), DNA fragmentation (D) and caspase-3/7 activity (E) were evaluated and are shown over time (6-24 h). The results are expressed as percentage of the untreated control and presented as mean values + SEM from three independent experiments. Flow cytometry analysis of annexin $\mathrm{V}$ (X-axis) and propidium iodide (Y-axis) stained cells after 48 hrs exposure to VLX 40 in RPMI 8226 S, 8226/Dox40, U-937 and HL-60 cells (F). In (G) the effect of VLX40 with and without caspase inhibitors DEVD-FMK and LEHD-FMK on annexin $V$ staining is shown in U-937 cells.

\section{Diagnosis-specific activity of VLX40 ex vivo}

To examine the activity spectrum of VLX40, its cytotoxic effect was studied in 96 samples of primary cancer patient tumor cells (PCPTC) from patients with a variety of solid tumors and hematological malignancies as well as in four samples of primary lymphocytes from healthy donors (PBMC). Median $\mathrm{IC}_{50}$-values ranged from $<1 \mu \mathrm{M}$ for diagnoses such as chronic lymphocytic leukemia (CLL), acute lymphocytic leukemia (ALL), acute myelocytic leukemia (AML), chronic myelocytic leukemia (CML) and lymphoma to $>34 \mu \mathrm{M}$ for breast, ovarian, colon, lung and renal cancer samples (Table 2). PBMC displayed intermediate sensitivity to VLX40. The in vitro response rates to VLX40 at 3.4 $\mu \mathrm{M}$ for the PCPTC of various diagnoses is displayed in Figure $4 \mathrm{~A}$. Consistent with the $\mathrm{IC}_{50}$ patterns in cell lines, leukemic malignancies showed the highest response rates followed by ovarian carcinoma and breast cancer whereas colon and renal cancer demonstrated the lowest response rates. Vincristine was included as a reference compound demonstrating a similar activity spectrum with lymphocytic leukemias being most sensitive. However, myelocytic leukemias were clearly less sensitive to vincristine, contrasting the high in vitro response rate obtained with VLX40.

The relative effect of VLX40 and six standard cytotoxic drugs, in solid and hematological tumor samples, expressed as the solid/hematological $(\mathrm{S} / \mathrm{H})$ ratio is shown in Figure $4 \mathrm{~B}$. VLX40 had a ratio of 0.28 indicating a modest activity against solid tumors compared to cisplatin ( $\mathrm{S} / \mathrm{H}$ ratio 1.2). All the remaining drugs showed $\mathrm{S} / \mathrm{H}$ ratios $<0.5$. The results for the standard drugs are consistent with their main clinical use. To roughly estimate tumor cell specificity, drug effects were compared in cells from CLL and normal PBMCs. VLX40 demonstrated a significantly higher activity against the malignant phenotype with a PBMC/CLL median $\mathrm{IC}_{50}$ ratio of 12.2 (Figure $4 \mathrm{C}$ ). Of the tested standard cytotoxic drugs only vincristine was more active in CLL than in PBMC.

To further evaluate and explain the relatively low activity of VLX40 on PCPTCs from solid tumors, which consists of multicellular clusters [21], we examined the ability of the compound to induce apoptosis of colon cancer cells grown as multicellular spheroids. As shown in Figure 4D, VLX40 showed a modest ability to induce apoptosis of cells in spheroids as evidenced by caspase-3 positive cells being mostly present in outer cell layers. The pattern was similar to that observed with vincristine (Figure 4D).

\section{VLX40 significantly inhibits in vivo growth of myeloid U-937 cells}

In vivo activity of VLX40 was investigated in hollow fiber cultures of myeloid U-937 cells subcutaneously implanted in mice (Figure 5). After a single dose of VLX40 $(2 \mu \mathrm{mol} /$ animal) significant $(\mathrm{p}<0.05)$ growth inhibition and tumor regression compared to vehicle treatment was observed. VLX40 showed no signs of toxicity at the doses tested.

\section{Discussion}

Genomics-based target identification and screening using cell free systems has been the dominating principle in cancer drug discovery during the recent decade [6]. As an alternative to this approach the use of phenotype-cell-based screening may provide some distinct advantages [35]. We here performed a conditional screen with the aim of identifying compounds that are cytotoxic to multidrug resistant myeloma cells. A chemically diverse compound library was used for this purpose. The screening hit RH02104/VLX40 was the only compound that fulfilled the pre-determined criteria of a SI less than $50 \%$ in myeloma 8226/Dox40 and more than 50\% in parental RPMI 8226 cells. In validation experiments VLX40 was found the difference was, albeit statistically significant, small. It can not be excluded that subtle differences in drug uptake and proliferation characteristics of the cell lines, not related to drug transporters, could contribute to the difference observed.

For exploration of mechanisms of action we used a bioinformatic approach using a drug specific gene expression signature to probe the cmap database [24]. The results indicated strong connections to tubulin-active agents. In vitro assays subsequently confirmed that VLX40 inhibits the polymerization of tubulin monomers and induces mitotic arrest.

A large number of tubulin active agents have been described in the literature, and some of these are important clinically used agents [36]. The majority of known tubulin inhibitors are natural products from many classes of 


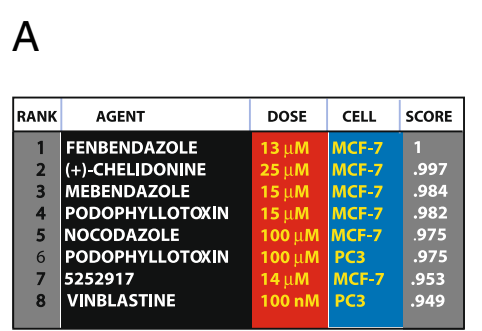

C

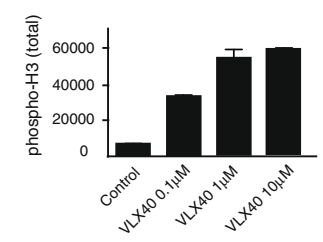

D RPMI8226
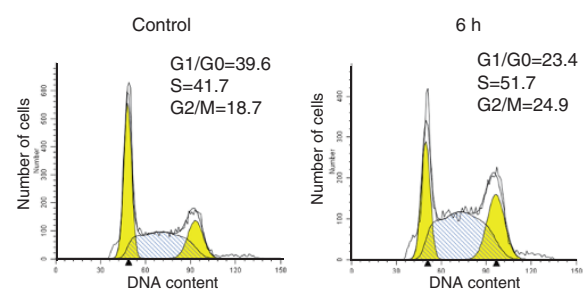

RPMI8226/Dox40

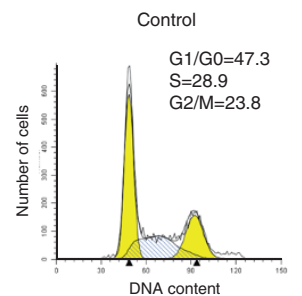

U937

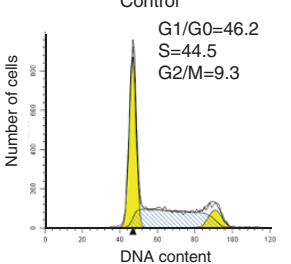

$\mathrm{HL}-60$

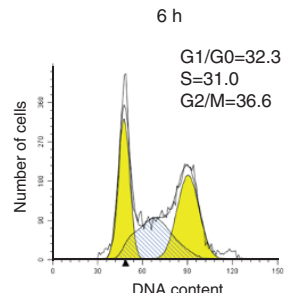

$6 \mathrm{~h}$
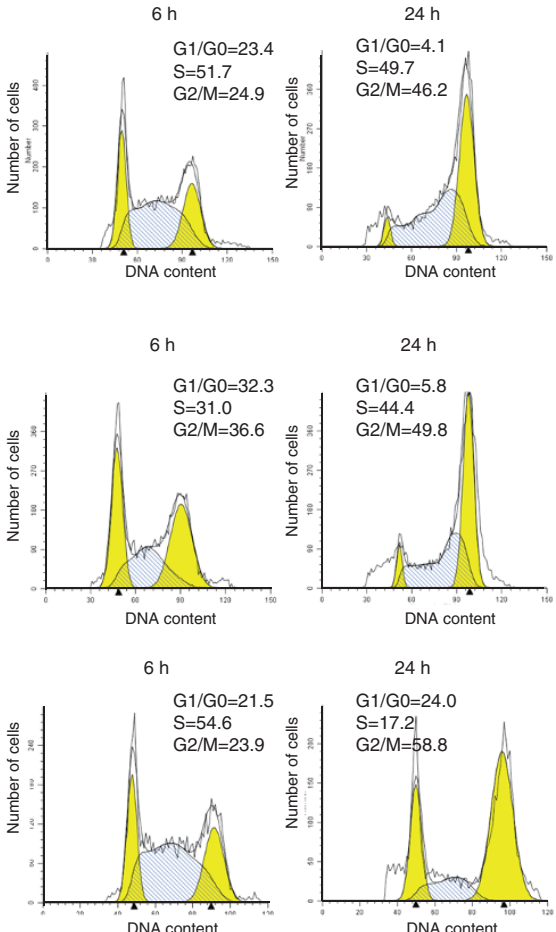

$24 \mathrm{~h}$

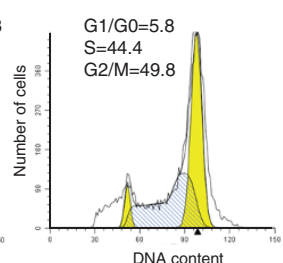

DNA content

$24 \mathrm{~h}$

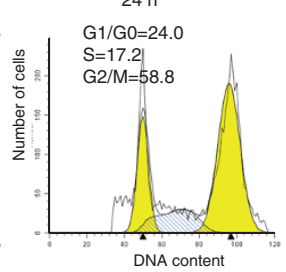

Control
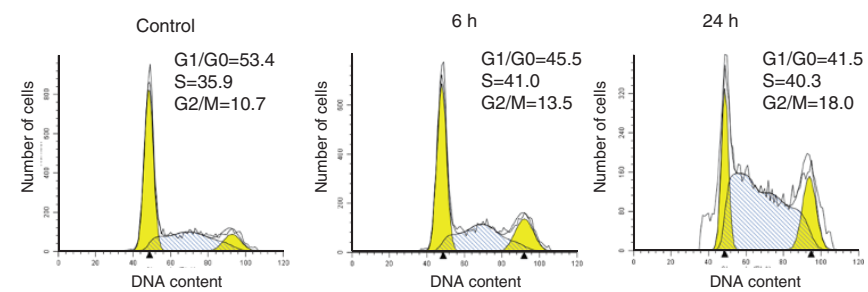

$E$

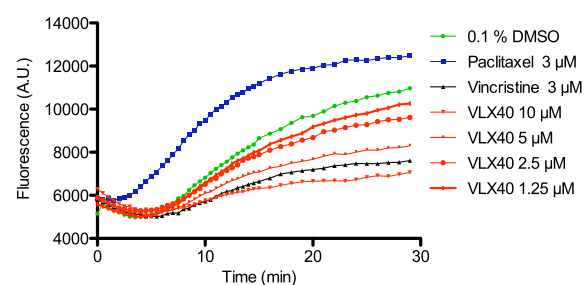

Figure $\mathbf{3}$ (See legend on next page.) 
(See figure on previous page.)

Figure 3 VLX40 is a tubulin active agent. (A) Microarray based mechanistic evaluation using Connectivity Map (cmap). MCF-7 cells were exposed to VLX40 for $6 \mathrm{~h}$ as described in experimental procedures. Out of the 6100 drug specific profiles in the data base, the eight most similar were all derived from compounds known to be tubulin inhibitors. 5252917 corresponds to N-(2-benzooxazol-2-yl-phenyl)-4-methylbenzenesulfonamide. Score according to cmap data base. (B) Gene Set Enrichment Analysis (GSEA) shows significant up-regulation of genes involved in mitosis. The pre-ranked gene list (VLX40 exposed MCF-7 cells vs. untreated control) was compared to a priori defined and curated gene sets. The purpose of GSEA is to find out whether the a priori defined gene sets are significantly enriched towards the upper or lower end of the pre-ranked list. The p-value refers to the nominal p-value after 1000 permutations. (C) Phospho-histone H3 staining using Arrayscan VTI (total intensity) after exposure to VLX40 for 24 hrs in HCT 116 cells. (D) Analysis of cell cycle distribution after 24 hrs exposure to VLX40 in DAPI stained RPMI 8226, 8226/Dox40, U-937 and HL-60 cells. (E) Confirmation of tubulin inhibition as the mechanism of action of VLX40 using a cell free assay for tubulin polymerization. Vincristine $(3 \mu \mathrm{M})$ and paclitaxel $(3 \mu \mathrm{M})$ were used as reference compounds.
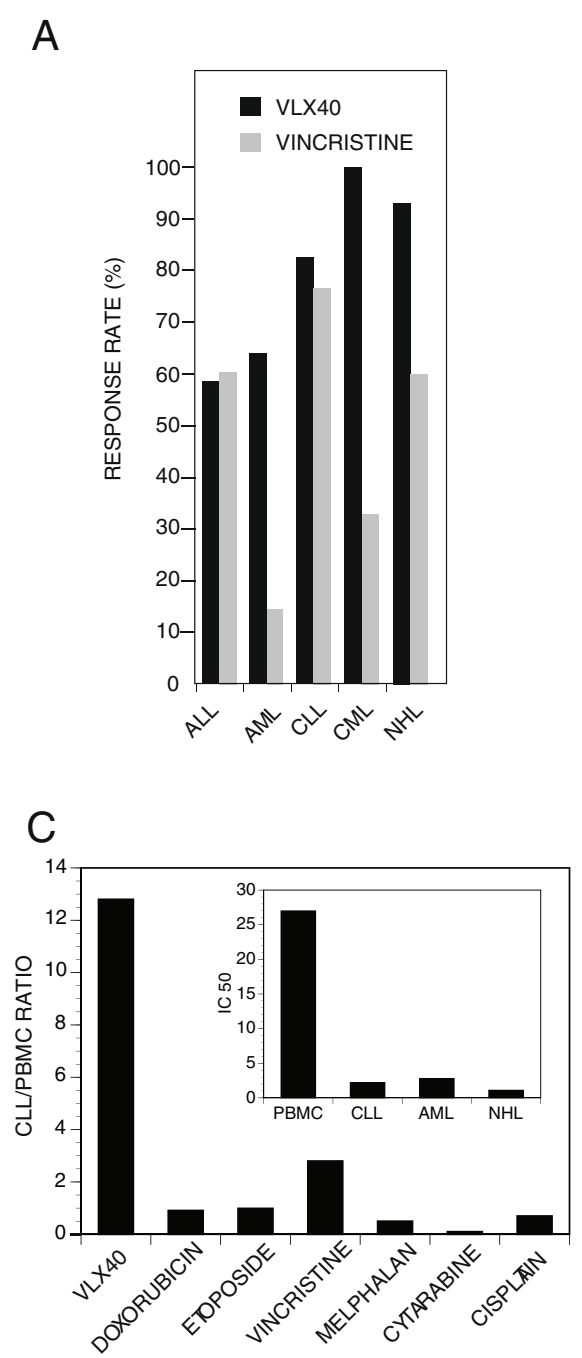

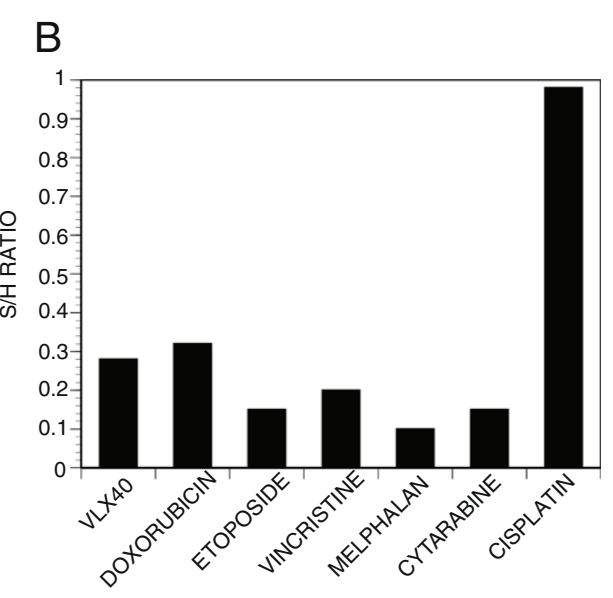

D

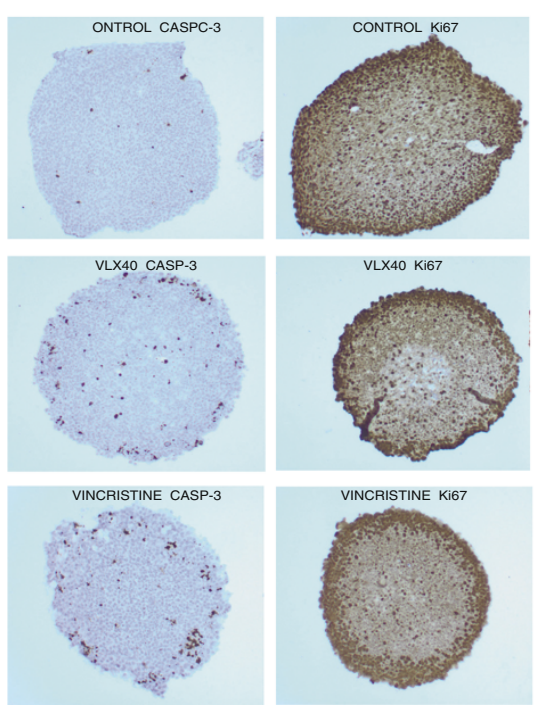

Figure 4 Ex vivo activity pattern of VLX40. (A) The ex vivo response rate in a panel of primary cultures of patient tumor cells (PCPTC) representing a range of diagnoses $(n=98)$ is shown. The concentrations used were $3.4 \mu M$ of VLX40 and $1 \mu M$ of vincristine. See material and methods for details. (B) The solid tumor/hematological tumor activity ratio ( $\mathrm{S} / \mathrm{H}$ ratio) is displayed for VLX40 and six standard agents $(\mathrm{n}=99)$. (C) The $I_{50}$ ratio between CLL $(n=9)$ and PBMC $(n=4)$ is shown for VLX40 and six standard drugs. (D) Caspase-3 induction in multicellular spheroids prepared from HCT116 colon carcinoma cells. Multicellular spheroids were treated for $24 \mathrm{~h}$, fixed, sectioned and stained for active caspase-3. Note the induction of apoptosis preferentially at peripheral cell layers. 

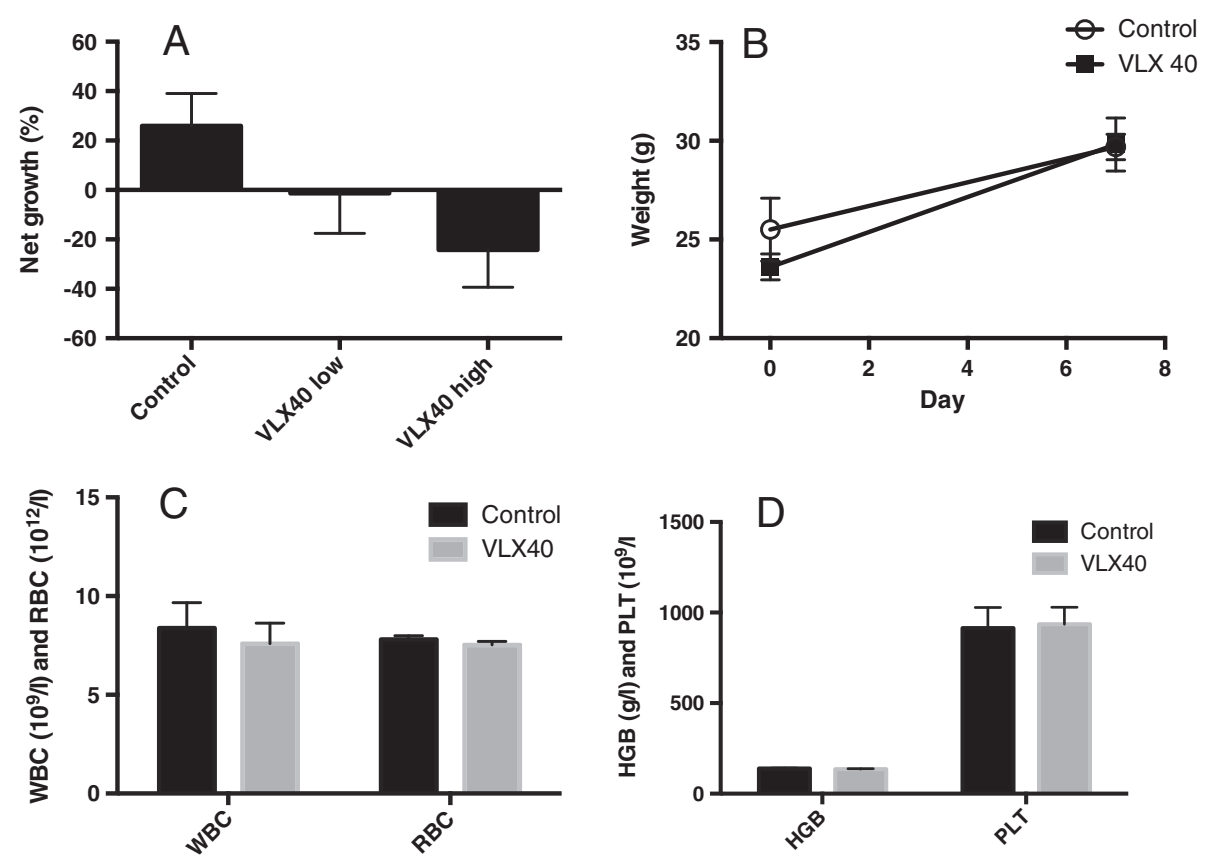

Figure 5 VLX40 shows in vivo activity in hollow fiber cultures. In A, the antitumoral effect of a single dose of VLX40 was investigated in mice ( $n=8$ per treatment group) carrying subcutaneous hollow fiber cultures of the myeloid cell line U-937. High and low refers to 2.0 and $0.5 \mu$ mol VLX40 per animal, respectively. The results are presented as net growth and expressed as mean value + S.E.M $(n=8)$. The difference between the high dose and control was statistically significant ( $p<0.05$, Student's $t$-test). In panels B-D the effect of the high dose VLX40 on weight gain (B), red and white blod cell count (C) and hemoglobin and platelet count (D) is shown.

organisms, suggesting that tubulin has been selected as a target by evolution at several independent occasions $[36,37]$. Interestingly, microtubule inhibitors have turned out to be significantly more successful in clinical practice compared to more recently developed mitosis-specific agents [38]. It has been suggested that the superior clinical efficacy of tubulin inhibitors is due to disruption of the function of microtubules in interphase cells [38].

Investigators have reported that microtubule inhibitors were identified in screens aimed to identify compounds directed at other targets, such as kinases [39], suggesting that tubulin polymerization may be a sensitive process that is easily targeted by a variety of chemical substances. Indeed, identification of tubulin inhibitors in screening diverse chemical libraries is not a rare event $[26,40]$. Nevertheless VLX40 showed a favorable pharmacological profile compared to vincristine being active against a multidrug resistant myeloma cell line with little sensitivity to other common forms of vinca alkaloid resistance.

VLX40 demonstrated a relatively narrow spectrum of activity in PCPTCs of various tumor types demonstrating activity preferentially in leukemias and lymphomas. Using PCPTCs with FMCA has demonstrated the ability to reflect tumor-type specific activity (25) as well as providing good clinical correlations $(15,16)$. The spectrum of anti-leukemic activity was clearly distinct of that observed for vincristine; the largest difference being observed for AML cells which were sensitive to VLX40 but insensitive to vincristine. This spectrum of vinca alkaloid activity closely corresponds to clinical activity [30]. In contrast, VLX40 showed very limited activity on ex vivo solid tumor cells from breast, ovary, lung, colon and renal cancer patients. The reason for the low activity observed in the PCPTC solid tumor models may, at least partly, be due a to poor drug penetration in the latter model system, consisting of multicellular clusters [21]. This was supported by the modest antitumor activity obtained in the 3-D spheroid model cell line. However, in addition to poor penetration into the deeper cell layers also limited sensitivity and low proliferation of cells in these layers could contribute to the low solid tumor activity observed.

$8226 /$ Dox40 were originally selected for resistance to doxorubicin and show cross-resistance to mitoxantrone, acronycine, etoposide, and vincristine $[11,15]$. The resistant subline strongly overexpresses the MDR1 gene product P-gp170 [11,15]. A study using expression microarrays has confirmed MDR1 mRNA overexpression and also showed down-regulation of a number of apoptotic-regulators, including caspase-3, the proapoptic regulator BAD and TNF-receptors [12]. We have reported upregulation of STAT1-regulated genes in the 8226/Dox40 cell line [13,14]. While P-gp170 is clearly involved in vincristine resistance 
[15], the role of down-regulation of apoptotic regulators in the resistance of $8226 /$ Dox40 to vincristine is more uncertain.

The high PBMC/CLL $\mathrm{IC}_{50}$ ratio indicates a potentially high therapeutic index ex vivo. It should be emphasized that both the PBMC/CLL ratio and $\mathrm{S} / \mathrm{H}$ ratios are in vitro indicators for therapeutic index and clinical activity spectra and should be evaluated in relative rather than absolute terms. A ratio of 1 indicates equal sensitivity for PBMC vs. CLL and solid vs hematological activity, respectively. Thus, comparing and ranking different drugs with respect to these measures is a preferable way to utilize these indices. Indeed, the $\mathrm{S} / \mathrm{H}$ index has previously been shown to correlate well to the clinical activity profile of standard cytotoxic cancer agents [41]. Both CLL and PBMC are largely non-proliferative under the present assay conditions. Furthermore, supporting these ex vivo findings VLX40 had significant in vivo activity against myeloid U-937 cells with no signs of toxicity. It should be noted that the hollow fiber is a very resistant in vivo tumor model requiring the drug to penetrate into fibers implanted deep subcutaneously, thus yielding a low false positive rate for cancer activity in vivo compared with other in vivo models [40]. However, the relatively low solubility of VLX40 in standard vehicles unfortunately limits the maximum dose that can be administered. Further work on improved formulations or analogue development may provide a potential future solution to this obstacle.

Chemically VLX40 is described as a 2-phenyl-4-hydroxyquinoline, which is a flavone-like element that has been used in medicinal chemistry previously, for example to design inhibitors of bacterial cell membrane pumps [42], or to inhibit cyclo-oxygenases [43]. Indeed several reports also demonstrate antiproliferative effects on human cancer cells, often as 2-phenyl-4-quinolones (isomers of 2phenyl-4-hydroxyquinolines). For example, Hadjeri and co-workers synthesized a series of 5-hydroxy-2-phenyl-4quinolones with potent antiproliferative activity in the NCI 60 cell line panel, and induced G2/M cell cycle arrest. Interestingly, the presence of a 5-hydroxy group (not present in VLX40) appeared to be important for these antiproliferative effects, which were not associated with microtubule inhibition [44]. However, others have shown that 2-phenyl-4-quinolones indeed do posses antimitotic activities, and that there is a good correlation between cytotoxicity of these compounds and their ability to inhibit tubulin polymerization [45-48].

The 2-phenyl-4-hydroxyquinolines are structurally unrelated to other tubulin inhibitors and may thus display other characteristics of importance for successful treatment, like spectrum of side effects or resistance. For example, vincristine is a substrate for both MRP and P-gp170, while VLX40 appears un-affected to both these mechanisms
(Figure 1C). Furthermore, myeloblasts are often inherently resistant to vincristine, a feature that has been attributed to their high myeloperoxidase activity and generation of hydrogen peroxide by oxidation of hypochlorus acid subsequently leading to vinca alkaloid degradation [49]. The results of this study confirm the inherent resistance of AML cells to vincristine (Figure 4A), but not to the structurally different VLX40.

\section{Conclusions}

In conclusion, the present study identified a novel tubulin active agent with retained activity in multidrug resistant models and which is active also against myeloid leukemia. VLX40 has a potential use as a cancer agent by virtue of its activity on drug resistant cells and may potentially be developed as an agent for AML. Further preclinical development will be required to evaluate its potential role as a novel prototype for future treatment of malignant diseases.

\section{Competing interests}

$J G, G W, P N$ and RL are co-founders and minor share-holders, MF and SL are minor share-holders, of Vivolux $A B$.

\section{Authors' contributions}

All authors were involved in designing experiments and interpreting data. MF, JG and and XW participated in most of the experiments and contributed equally to this work. RL, PN and SL have been involved in the overall design of the study and drafting major parts of the manuscript. MW and MJ performed the arrayscan experiments. LR designed and performed the primary screen. CA and MG created the screening database structure and provided bioinformatic support. SH performed the in vivo hollow fiber assay. GW contributed to the chemical aspects of the study with his expertise in medicinal chemistry. All authors read and approved the final manuscript.

\section{Acknowledgements}

We are grateful for all the work with microarray array analysis at the Uppsala Expression Array Platform. The skillful technical assistance of Christina Leek and Lena Lenhammar is gratefully acknowledged. This study was supported by the Swedish Cancer Society (S.L., P.N., and R.L.), Radiumhemmets forskningsfonder and the Swedish Research Council (S.L.) and the Lions Cancer Research Fund (P.N. and R.L.).

\section{Author details}

'Department of Medical Sciences, Division of Clinical Pharmacology, Uppsala University, S-751 85 Uppsala, Sweden. ²Department of Oncology, Radiology and Clinical Immunology, Uppsala University, S-751 85 Uppsala, Sweden. ${ }^{3}$ Department of Oncology-Pathology, Cancer Center Karolinska, Karolinska Institute, Stockholm, Sweden. ${ }^{4}$ Department of Chemical and Biological Engineering, Chalmers University of Technology, S-412 96 Gothenburg, Sweden.

Received: 31 May 2013 Accepted: 24 July 2013

Published: 6 August 2013

\section{References}

1. Hait WN, Yang JM: Clinical management of recurrent breast cancer: development of multidrug resistance (MDR) and strategies to circumvent it. Semin Oncol 2005, 32(6 Suppl 7):S16-21.

2. Kavallaris M, Annereau JP, Barret JM: Potential mechanisms of resistance to microtubule inhibitors. Semin Oncol 2008, 35(3 Suppl 3):S22-27.

3. Ling V: Multidrug resistance: molecular mechanisms and clinical relevance. Cancer Chemother Pharmacol 1997, 40(Suppl):S3-8.

4. Fodale $V$, Pierobon M, Liotta L, Petricoin E: Mechanism of cell adaptation: when and how do cancer cells develop chemoresistance? Cancer J 2011, 17(2):89-95 
5. Lu H-P, Chao CCK: Cancer cells acquire resistance to anticancer drugs: an update. Biomed J 2012, 35(6):464-472.

6. Fox S, Farr-Jones S, Sopchak L, Boggs A, Nicely HW, Khoury R, Biros M: Highthroughput screening: update on practices and success. J Biomol Screen 2006, 11(7):864-869.

7. Dhar S, Gullbo J, Nilsson K, Nygren P, Larsson R: A Nonclonogenic Cytotoxicity Assay Using Primary Cultures of Patient Tumor Cells for Anticancer Drug Screening. J Biomol Screen 1998, 3(3):207-216.

8. Hart CP: Finding the target after screening the phenotype. Drug Discov Today 2005, 10(7):513-519.

9. Sharma SV, Haber DA, Settleman J: Cell line-based platforms to evaluate the therapeutic efficacy of candidate anticancer agents. Nat Rev Cancer 2010, 10(4):241-253.

10. Rickardson L, Fryknas M, Haglund C, Lovborg H, Nygren P, Gustafsson MG, Isaksson A, Larsson R: Screening of an annotated compound library for drug activity in a resistant myeloma cell line. Cancer Chemother Pharmacol 2006, 58(6):749-758.

11. Tong AW, Lee J, Wang RM, Dalton WS, Tsuruo T, Fay JW, Stone MJ: Elimination of chemoresistant multiple myeloma clonogenic colonyforming cells by combined treatment with a plasma cell-reactive monoclonal antibody and a P-glycoprotein-reactive monoclonal antibody. Cancer Res 1989, 49(17):4829-4834.

12. Watts GS, Futscher BW, Isett R, Gleason-Guzman M, Kunkel MW, Salmon SE CDNA microarray analysis of multidrug resistance: doxorubicin selection produces multiple defects in apoptosis signaling pathways. J Pharmacol Exp Ther 2001, 299(2):434-441.

13. Fryknas $M$, Dhar $S$, Oberg F, Rickardson L, Rydaker M, Goransson $H$, Gustafsson M, Pettersson U, Nygren P, Larsson R, et al: STAT1 signaling is associated with acquired crossresistance to doxorubicin and radiation in myeloma cell lines. Int J Cancer 2007, 120(1):189-195.

14. Rickardson L, Fryknas M, Dhar S, Lovborg H, Gullbo J, Rydaker M, Nygren P, Gustafsson MG, Larsson R, Isaksson A: Identification of molecular mechanisms for cellular drug resistance by combining drug activity and gene expression profiles. Br J Cancer 2005, 93(4):483-492.

15. Dalton WS, Grogan TM, Rybski JA, Scheper RJ, Richter L, Kailey J, Broxterman $\mathrm{HJ}$, Pinedo HM, Salmon SE: Immunohistochemical detection and quantitation of P-glycoprotein in multiple drug-resistant human myeloma cells: association with level of drug resistance and drug accumulation. Blood 1989, 73(3):747-752.

16. Mulcahy RT, Bailey HH, Gipp JJ: Up-regulation of gamma-glutamylcyateine synthtase activity in melphalan-resitant human multiple myeloma cells expressing increased glutathione levels. Cancer Chemother Pharmacol 1994, 34:67-71.

17. Beck WT, Cirtain MC, Danks MK, Felsted RL, Safa AR, Wolverton JS, Suttle DP, Trent JM: Pharmacological, molecular, and cytogenetic analysis of "atypical" multidrug-resistant human leukemic cells. Cancer Res 1987, 47(20):5455-5460.

18. Mirski SE, Gerlach JH, Cole SP: Multidrug resistance in a human small cell lung cancer cell line selected in adriamycin. Cancer Res 1987. 47(10):2594-2598.

19. Botling J, Liminga G, Larsson R, Nygren P, Nilsson K: Development of vincristine resistance and increased sensitivity to cyclosporin $A$ and verapamil in the human $\mathrm{U}-937$ lymphoma cell line without overexpression of the 170-kDa P-glycoprotein. Int J Cancer 1994, 58(2):269-274.

20. Larsson R, Kristensen J, Sandberg C, Nygren P: Laboratory determination of chemotherapeutic drug resistance in tumor cells from patients with leukemia, using a fluorometric microculture cytotoxicity assay (FMCA). Int J Cancer 1992, 50(2):177-185.

21. Csoka K, Larsson R, Tholander B, Gerdin E, de la Torre M, Nygren P: Cytotoxic drug sensitivity testing of tumor cells from patients with ovarian carcinoma using the fluorometric microculture cytotoxicity assay (FMCA). Gynecol Oncol 1994, 54(2):163-170.

22. Lindhagen $E$, Nygren $P$, Larsson $R$ : The fluorometric microculture cytotoxicity assay. Nat Protoc 2008, 3(8):1364-1369.

23. Lovborg H, Nygren P, Larsson R: Multiparametric evaluation of apoptosis: effects of standard cytotoxic agents and the cyanoguanidine CHS 828 . Mol Cancer Ther 2004, 3(5):521-526.

24. Lamb J, Crawford ED, Peck D, Modell JW, Blat IC, Wrobel MJ, Lerner J, Brunet JP, Subramanian A, Ross KN, et al: The Connectivity Map: using gene-expression signatures to connect small molecules, genes, and disease. Science 2006, 313(5795):1929-1935.
25. Subramanian A, Tamayo P, Mootha VK, Mukherjee S, Ebert BL, Gillette MA, Paulovich A, Pomeroy SL, Golub TR, Lander ES, et al: Gene set enrichment analysis: a knowledge-based approach for interpreting genome-wide expression profiles. Proc Natl Acad Sci USA 2005, 102(43):15545-15550.

26. Fayad W, Rickardson L, Haglund C, Olofsson MH, D'Arcy P, Larsson R, Linder $S$, Fryknas M: Identification of agents that induce apoptosis of multicellular tumour spheroids: enrichment for mitotic inhibitors with hydrophobic properties. Chem Biol Drug Des 2011, 78(4):547-557.

27. Friberg LE, Hassan $S B$, Lindhagen $E$, Larsson R, Karlsson MO: Pharmacokinetic-pharmacodynamic modelling of the scheduledependent effect of the anti-cancer agent CHS 828 in a rat hollow fibre model. Eur J Pharm Sci 2005, 25(1):163-173.

28. Jonsson E, Friberg LE, Karlsson MO, Hassan SB, Freijs A, Hansen K, Larsson R: Determination of drug effect on tumour cells, host animal toxicity and drug pharmacokinetics in a hollow-fibre model in rats. Cancer Chemother Pharmacol 2000, 46(6):493-500.

29. Scudiero DA, Shoemaker RH, Paull KD, Monks A, Tierney S, Nofziger TH, Currens MJ, Seniff D, Boyd MR: Evaluation of a soluble tetrazolium/ formazan assay for cell growth and drug sensitivity in culture using human and other tumor cell lines. Cancer Res 1988, 48(17):4827-4833.

30. Haglund C, Aleskog A, Nygren P, Gullbo J, Hoglund M, Wickstrom M, Larsson $R$, Lindhagen E: In vitro evaluation of clinical activity and toxicity of anticancer drugs using tumor cells from patients and cells representing normal tissues. Cancer Chemother Pharmacol 2012, 69(3):697-707.

31. Friedman PA, Platzer EG: Interaction of anthelmintic benzimidazoles and benzimidazole derivatives with bovine brain tubulin. Biochim Biophys Acta 1978, 544(3):605-614.

32. Jordan MA, Thrower $D$, Wilson $L$ : Effects of vinblastine, podophyllotoxin and nocodazole on mitotic spindles. Implications for the role of microtubule dynamics in mitosis. J Cell SCi 1992, 102(Pt 3):401-416.

33. Koeller KM, Haggarty SJ, Perkins BD, Leykin I, Wong JC, Kao MC, Schreiber SL: Chemical genetic modifier screens: small molecule trichostatin suppressors as probes of intracellular histone and tubulin acetylation. Chem Biol 2003, 10(5):397-410.

34. Panzer A, Joubert AM, Bianchi PC, Hamel E, Seegers JC: The effects of chelidonine on tubulin polymerisation, cell cycle progression and selected signal transmission pathways. Eur J Cell Biol 2001, 80(1):111-118.

35. Root DE, Flaherty SP, Kelley BP, Stockwell BR: Biological mechanism profiling using an annotated compound library. Chem Biol 2003, 10(9):881-892

36. Hamel E: Antimitotic natural products and their interactions with tubulin. Med Res Rev 1996, 16(2):207-231.

37. Giannakakou P, Sackett D, Fojo T: Tubulin/microtubules: still a promising target for new chemotherapeutic agents. J Natl Cancer Inst 2000, 92(3):182-183.

38. Komlodi-Pasztor E, Sackett D, Wilkerson J, Fojo T: Mitosis is not a key target of microtubule agents in patient tumors. Nat Rev Clin Oncol 2011, 8(4):244-250.

39. Ross-Macdonald P, de Silva $\mathrm{H}$, Guo $\mathrm{Q}$, Xiao $\mathrm{H}$, Hung CY, Penhallow B, Markwalder J, He L, Attar RM, Lin TA, et al: Identification of a nonkinase target mediating cytotoxicity of novel kinase inhibitors. Mol Cancer Ther 2008, 7(11):3490-3498.

40. Yang WS, Shimada K, Delva D, Patel M, Ode E, Skouta R, Stockwell BR: Identification of Simple Compounds with Microtubule-Binding Activity That Inhibit Cancer Cell Growth with High Potency. ACS Med Chem Lett 2012, 3(1):35-38.

41. Fridborg H, Jonsson E, Nygren P, Larsson R: Relationship between diagnosis-specific activity of cytotoxic drugs in fresh human tumour cells ex vivo and in the clinic. Eur J Cancer 1999, 35(3):424-432.

42. Sabatini S, Gosetto F, Manfroni G, Tabarrini O, Kaatz GW, Patel D, Cecchetti V: Evolution from a natural flavones nucleus to obtain 2-(4-Propoxyphenyl) quinoline derivatives as potent inhibitors of the $\mathrm{S}$. aureus NorA efflux pump. J Med Chem 2011, 54(16):5722-5736.

43. Liao $\mathrm{CH}$, Chang $\mathrm{YL}$, Guh $J H$, Kuo SC, Huang LJ, Teng CM: Effect of a potent cyclooxygenase inhibitor, 5-ethyl-4-methoxy-2-phenylquinoline (KTC-5), on human platelets. J Pharm Pharmacol 2002, 54(7):967-974.

44. Hadjeri M, Peiller EL, Beney C, Deka N, Lawson MA, Dumontet C, Boumendjel A: Antimitotic activity of 5-hydroxy-7-methoxy-2-phenyl-4-quinolones. J Med Chem 2004, 47(20):4964-4970. 
45. Kuo SC, Lee HZ, Juang JP, Lin YT, Wu TS, Chang JJ, Lednicer D, Paull KD, Lin CM, Hamel E, et al: Synthesis and cytotoxicity of 1,6,7,8-substituted 2-(4'-substituted phenyl)-4-quinolones and related compounds: identification as antimitotic agents interacting with tubulin. J Med Chem 1993, 36(9):1146-1156.

46. Li L, Wang HK, Kuo SC, Wu TS, Lednicer D, Lin CM, Hamel E, Lee KH: Antitumor agents. 150. 2',3',4',5',5,6,7-substituted 2-phenyl-4-quinolones and related compounds: their synthesis, cytotoxicity, and inhibition of tubulin polymerization. J Med Chem 1994, 37(8):1126-1135.

47. Xia Y, Yang ZY, Xia P, Bastow KF, Nakanishi Y, Nampoothiri P, Hamel E, Brossi A, Lee KH: Antitumor agents. Part 226: synthesis and cytotoxicity of 2-phenyl-4-quinolone acetic acids and their esters. Bioorg Med Chem Lett 2003, 13(17):2891-2893.

48. Xia Y, Yang ZY, Xia P, Bastow KF, Tachibana Y, Kuo SC, Hamel E, Hackl T, Lee KH: Antitumor agents. 181. Synthesis and biological evaluation of 6,7,2',3',4'-substituted-1,2,3,4-tetrahydro-2-phenyl-4-quinolones as a new class of antimitotic antitumor agents. J Med Chem 1998, 41(7):1155-1162

49. Ozgen U, Savasan S, Stout M, Buck S, Ravindranath Y: Further elucidation of mechanism of resistance to vincristine in myeloid cells: role of hypochlorous acid in degradation of vincristine by myeloperoxidase. Leukemia 2000, 14(1):47-51.

doi:10.1186/1471-2407-13-374

Cite this article as: Fryknäs et al.: Screening for phenotype selective activity in multidrug resistant cells identifies a novel tubulin active agent insensitive to common forms of cancer drug resistance. $B M C$ Cancer 2013 13:374.

\section{Submit your next manuscript to BioMed Central and take full advantage of:}

- Convenient online submission

- Thorough peer review

- No space constraints or color figure charges

- Immediate publication on acceptance

- Inclusion in PubMed, CAS, Scopus and Google Scholar

- Research which is freely available for redistribution 